\title{
SISTEMA INTERAMERICANO DE DIREITOS HUMANOS: IMPACTO TRANSFORMADOR, DIÁLOGOS JURISDICIONAIS E OS DESAFIOS DA REFORMA
}

\author{
INTER-AMERICAN SYSTEM OF HUMAN RIGHTS: \\ IMPACT TRANSFORMER, DIALOGUE AND THE CHALLENGES OF JUDICIAL \\ REFORM
}

FLÁVIA POIOVESAN

Professora doutora em Direito Constitucional e Direitos Humanos da Pontifícia Universidade Católica de São Paulo, Professora de Direitos Humanos dos Programas de Pós Graduação da Pontifícia Universidade Católica de São Paulo, da Pontifícia Universidade Católica do Paraná e da Universidade Pablo de Olavide (Sevilha, Espanha).

flaviapiovesan@terra.com.br

\begin{abstract}
RESUMO
Objetiva este artigo enfocar o sistema interamericano de direitos humanos, com destaque ao seu impacto transformador no contexto latino-americano e seu crescente empoderamento na região, fruto da efetividade do diálogo jurisdicional em um sistema multinível. É sob esta perspectiva multinível que emergem quatro vertentes do diálogo jurisdicional, a compreender o diálogo com o sistema global (mediante a incorporação de parâmetros protetivos de direitos humanos); o diálogo com os sistemas regionais (a envolver a "europeicização" do sistema interamericano e a "interamericanização" do sistema europeu); o diálogo com os sistemas nacionais (a abranger o controle da convencionalidade); e o diálogo com a sociedade civil (a emprestar ao sistema interamericano crescente legitimação social). Pretende-se identificar os principais desafios do sistema interamericano e os potenciais riscos de sua agenda de reformas visando ao fortalecimento do sistema e à pavimentação de um ius commune latinoamericano em matéria de direitos humanos.
\end{abstract}

Palavras-chave: Direitos Humanos; Sistema Interamericano; Reforma; Contexto Latino-americano;

\begin{abstract}
This article aims to focus on the inter-American human rights system, especially its transformative impact on the Latin American context and their growing empowerment in the region because of the effectiveness of the judicial dialogue in a multilevel system. It is under this multilevel perspective that emerge four aspects of the judicial dialogue, to understand the dialogue with the global system (by incorporating protective parameters of human rights); dialogue with regional systems (to involve "europe" American system and the "interamerican" the European system); dialogue with national systems (to include control of conventionality); and dialogue with civil society (to borrow American system growing social legitimacy). It is intended to identify the main challenges of the inter-American system and the potential risks of its reform agenda aimed at strengthening the system and the paving of a ius commune Hispanic on human rights.
\end{abstract}

Keywords: Human Rights; Inter-American system; reform; Latin American context; 


\section{SUMÁRIO}

INTRODUÇAO; 1 IMPACTO TRANSFORMADOR DO SISTEMA INTERAMERICANO NO CONTEXTO LATINOAMERICANO; 2 O EMPODERAMENTO DO SISTEMA INTERAMERICANO MEDIANTE A EFETIVIDADE DO DIÁLOGO JURISDICIONAL E CRESCENTE LEGITIMAÇÃO SOCIAL; 3 DESAFIOS DO SISTEMA INTERAMERICANO, AGENDA DE REFORMAS E A PAVIMENTAÇÃO DE UM “IUS COMMUNE LATINOAMERICANO EN DERECHOS HUMANOS"; REFERÊNCIAS.

\section{INTRODUÇÃO}

Objetiva este artigo enfocar o sistema interamericano de direitos humanos, com destaque ao seu impacto transformador no contexto latino-americano e seu crescente empoderamento na região, fruto da efetividade do diálogo jurisdicional em um sistema multinível.

É sob esta perspectiva multinível que emergem quatro vertentes do diálogo jurisdicional, a compreender o diálogo com o sistema global (mediante a incorporação de parâmetros protetivos de direitos humanos); o diálogo com os sistemas regionais (a envolver a "europeicização" do sistema interamericano e a "interamericanização" do sistema europeu); o diálogo com os sistemas nacionais (a abranger o controle da convencionalidade); e o diálogo com a sociedade civil (a emprestar ao sistema interamericano crescente legitimação social).

Por fim, pretende-se identificar os principais desafios do sistema interamericano e os potenciais riscos de sua agenda de reformas visando ao fortalecimento do sistema e à pavimentação de um ius commune latino-americano em matéria de direitos humanos.

\section{IMPACTO TRANSFORMADOR DO SISTEMA INTERAMERICANO NO CONTEXTO LATINO-AMERICANO}

A América Latina ostenta o maior grau de desigualdade do mundo. A pobreza na região diminuiu do patamar de 48,3\% a 33,2\%, no período de 1990 e 2008 . Cinco dos dez países mais desiguais do mundo estão na América Latina, dentre eles o Brasil ${ }^{1}$.

\footnotetext{
${ }^{1}$ Marta Lagos e Lucía Dammert, La Seguridad Ciudadana: El problema principal de América Latina, Latinobarómetro, 9 de maio de 2012, p.3.

REDESG / Revista Direitos Emergentes na Sociedade Global - www.ufsm.br/redesg v. 3, n. 1, jan.jun/2014
} 
SISTEMA INTERAMERICANO DE DIREITOS HUMANOS: IMPACTO TRANSFORMADOR, DIÁLOGOS JURISDICIONAIS E OS DESAFIOS DA REFORMA

Não bastando o acentuado grau de desigualdade, a região ainda se destaca por ser a mais violenta do mundo. Concentra $27 \%$ dos homicídios, tendo apenas $9 \%$ da população mundial. Dez dos vinte países com maiores taxas de homicídio do mundo são latino-americanos².

Como a região tem avançado não somente na diminuição da pobreza, como também na formação de uma classe média incipiente neste panorama de desigualdade, a segurança surge como o principal problema da América Latina. Em 11 de 18 países analisados pelo Latinobarometro a segurança constitui o desafio que os cidadãos mencionam como mais relevante a ser enfrentado pelos Estados (por exemplo, 61\% na Venezuela, com uma média regional de $28 \%$ ).

$\mathrm{Na}$ pesquisa Latinobarometro 2011 sobre o apoio à democracia na América Latina, baseada na pergunta "La democracia es preferible a cualquer outra forma de gobierno", a resposta afirmativa encontra no Brasil o endosso de apenas $45 \%$, no México $40 \%$ e na Guatemala $36 \%{ }^{3}$

A região latino-americana tem assim sido caracterizada por elevado grau de exclusão e violência ao qual se somam democracias em fase de consolidação. A região ainda convive com as reminiscências do legado dos regimes autoritários ditatoriais, com uma cultura de violência e de impunidade, com a baixa densidade de Estados de Direitos e com a precária tradição de respeito aos direitos humanos no âmbito doméstico.

Dois períodos demarcam o contexto latino-americano: o período dos regimes ditatoriais; e o período da transição política aos regimes democráticos, marcado pelo fim das ditaduras militares na década de 80, na Argentina, no Chile, no Uruguai e no Brasil.

Em 1978, quando a Convenção Americana de Direitos Humanos entrou em vigor, muitos dos Estados da América Central e do Sul eram governados por ditaduras. Dos 11 Estados-partes da Convenção à época, menos que a metade tinha governos eleitos democraticamente, ao passo que hoje quase a totalidade dos Estados latino-americanos na região tem governos eleitos democraticamente ${ }^{4}$. Diversamente do sistema regional europeu que teve como fonte inspiradora

\footnotetext{
2 Marta Lagos e Lucía Dammert, La Seguridad Ciudadana: El problema principal de América Latina, Latinobarómetro, 9 de maio de 2012, p.3.

${ }^{3}$ Latinobarómetro, Informe 2011, Santiago do Chile, 28 de outubro de 2012.

${ }^{4}$ Como observa Thomas Buergenthal: "O fato de hoje quase a totalidade dos Estados latino-americanos na região, com exceção de Cuba, terem governos eleitos democraticamente tem produzido significativos avanços na situação dos direitos humanos nesses Estados. Estes Estados ratificaram a Convenção e reconheceram a competência jurisdicional da Corte". (Prefácio de Thomas Buergenthal, Jo M. Pasqualucci, The Practice and Procedure of the Inter-American Court on Human Rights, Cambridge, REDESG / Revista Direitos Emergentes na Sociedade Global - www.ufsm.br/redesg v. 3, n. 1, jan.jun/2014
} 
SISTEMA INTERAMERICANO DE DIREITOS HUMANOS: IMPACTO TRANSFORMADOR, DIÁLOGOS JURISDICIONAIS E OS DESAFIOS DA REFORMA

a tríade indissociável Estado de Direito, Democracia e Direitos Humanos, o sistema regional interamericano tem em sua origem o paradoxo de nascer em um ambiente acentuadamente autoritário, que não permitia qualquer associação direta e imediata entre Democracia, Estado de Direito e Direitos Humanos. Ademais, neste contexto, os direitos humanos eram tradicionalmente concebidos como uma agenda contra o Estado. Diversamente do sistema europeu, que surge como fruto do processo de integração européia e tem servido como relevante instrumento para fortalecer este processo de integração, no caso interamericano havia tão somente um movimento ainda embrionário de integração regional.

É neste cenário que o sistema interamericano gradativamente se legitima como importante e eficaz instrumento para a proteção dos direitos humanos, quando as instituições nacionais se mostram falhas ou omissas. Com a atuação da sociedade civil, a partir de articuladas e competentes estratégias de litigância, o sistema interamericano tem a força catalizadora de promover avanços no regime de direitos humanos.

Permitiu a desestabilização dos regimes ditatoriais; exigiu justiça e o fim da impunidade nas transições democráticas; e agora demanda o fortalecimento das instituições democráticas com o necessário combate às violações de direitos humanos e proteção aos grupos mais vulneráveis.

Considerando a atuação da Corte Interamericana, é possível criar uma tipologia de casos baseada em decisões concernentes a 6 (seis) diferentes categorias de violação a direitos humanos:

\section{1) Violações que refletem o legado do regime autoritário ditatorial}

Esta categoria compreende a maioria significativa das decisões da Corte Interamericana, que tem por objetivo prevenir arbitrariedades e controlar o excessivo uso da força, impondo limites ao poder punitivo do Estado.

A título de exemplo, destaca-se o leading case - Velasquez Rodriguez versus Honduras concernente a desaparecimento forçado. Em 1989 a Corte condenou o Estado de Honduras a

Cambridge University Press, 2003, p.XV). Em 2012, 22 Estados haviam reconhecido a competência da Corte Interamericana de Humanos. De acordo com: http://www.cidh.oas.org/Basicos/English/Basic4.Amer.Conv.Ratif.htm (acesso em 06/01/12) 
pagar uma compensação aos familiares da vítima, bem como ao dever de prevenir, investigar, processar, punir e reparar as violações cometidas ${ }^{5}$.

Adicionem-se ainda decisões da Corte que condenaram Estados em face de precárias e cruéis condições de detenção e da violação à integridade física, psíquica e moral de pessoas detidas; ou em face da prática de execução sumária e extrajudicial; ou tortura. Estas decisões enfatizaram o dever do Estado de investigar, processar e punir os responsáveis pelas violações, bem como de efetuar o pagamento de indenizações.

No plano consultivo, merecem menção as opiniões a respeito da impossibilidade de adoção da pena de morte pelo Estado da Guatemala $^{6}$ e da impossibilidade de suspensão da garantia judicial de habeas corpus inclusive em situações de emergência, de acordo com o artigo 27 da Convenção Americana ${ }^{7}$.

\section{2) Violações que refletem questões da justiça de transição (transitional justice)}

Nesta categoria de casos estão as decisões relativas ao combate à impunidade, às leis de anistia e ao direito à verdade.

No caso Barrios Altos (massacre que envolveu a execução de 15 pessoas por agentes policiais), em virtude da promulgação e aplicação de leis de anistia (uma que concede anistia geral aos militares, policiais e civis, e outra que dispõe sobre a interpretação e alcance da anistia), o Peru foi condenado a reabrir investigações judiciais sobre os fatos em questão, relativos ao "massacre de Barrios Altos", de forma a derrogar ou a tornar sem efeito as leis de anistia mencionadas. O Peru foi condenado, ainda, à reparação integral e adequada dos danos materiais e morais sofridos pelos familiares das vítimas ${ }^{8}$.

Esta decisão apresentou um elevado impacto na anulação de leis de anistia e na consolidação do direito à verdade, pelo qual os familiares das vítimas e a sociedade como um todo devem ser informados das violações, realçando o dever do Estado de investigar, processar, punir e reparar violações aos direitos humanos.

Concluiu a Corte que as leis de "auto-anistia" perpetuam a impunidade, propiciam uma injustiça continuada, impedem às vítimas e aos seus familiares o acesso à justiça e o direito de

\footnotetext{
${ }^{5}$ Velasquez Rodriguez Case, Inter-American Court of Human Rights, 1988, Ser. C, No. 4.

${ }^{6}$ Advisory Opinion No. 3/83, of 8 September 1983.

${ }^{7}$ Advisory Opinion No. 08/87, of 30 January 1987.

${ }^{8}$ Barrios Altos case (Chumbipuma Aguirre and others vs. Peru). Judgment of 14 March 2001.

REDESG / Revista Direitos Emergentes na Sociedade Global - www.ufsm.br/redesg v. 3, n. 1, jan.jun/2014
} 
SISTEMA INTERAMERICANO DE DIREITOS HUMANOS: IMPACTO TRANSFORMADOR, DIÁLOGOS JURISDICIONAIS E OS DESAFIOS DA REFORMA

conhecer a verdade e de receber a reparação correspondente, o que constituiria uma manifesta afronta à Convenção Americana. As leis de anistiam configurariam, assim, um ilícito internacional e sua revogação uma forma de reparação não pecuniária.

No mesmo sentido, destaca-se o caso Almonacid Arellano versus Chile ${ }^{9}$ cujo objeto era a validade do decreto-lei 2191/78 -- que perdoava os crimes cometidos entre 1973 e 1978 durante o regime Pinochet -- à luz das obrigações decorrentes da Convenção Americana de Direitos Humanos. Decidiu a Corte pela invalidade do mencionado decreto lei de "auto-anistia", por implicar a denegação de justiça às vítimas, bem como por afrontar os deveres do Estado de investigar, processar, punir e reparar graves violações de direitos humanos que constituem crimes de lesa humanidade.

Cite-se, ainda, o caso argentino, em que decisão da Corte Suprema de Justiça de 2005 anulou as leis de ponto final (Lei 23.492/86) e obediência devida (Lei 23.521/87), adotando como precedente o caso Barrios Alto.

Em 2010, no caso Gomes Lund e outros versus Brasil, a Corte Interamericana condenou o Brasil em virtude do desaparecimento de integrantes da guerrilha do Araguaia durante as operações militares ocorridas na década de $70^{10}$. A Corte realçou que as disposições da lei de anistia de 1979 são manifestamente incompatíveis com a Convenção Americana, carecem de efeitos jurídicos e não podem seguir representando um obstáculo para a investigação de graves violações de direitos humanos, nem para a identificação e punição dos responsáveis. Enfatizou que leis de anistia relativas a graves violações de direitos humanos são incompatíveis com o Direito Internacional e as obrigações jurídicas internacionais contraídas pelos Estados. Concluiu, uma vez mais, que as leis de anistia violam o dever internacional do Estado de investigar e punir graves violações a direitos humanos.

Na mesma direção, em 2011, no caso Gelman versus Uruguai ${ }^{11}$, a Corte Interamericana decidiu que a "Lei de Caducidade da Pretensão Punitiva" carecia de efeitos jurídicos por sua incompatibilidade com a Convenção Americana e com a Convenção Interamericana sobre o

\footnotetext{
${ }^{9}$ Caso Almonacid Arellano and others vs. Chile. Judgment of 26 September 2006.

${ }^{10}$ Caso Gomes Lund and others versus Brasil, Judgment of 24 November 2010. O caso foi submetido à Corte pela Comissão Interamericana, ao reconhecer que o caso "representava uma oportunidade importante para consolidar a jurisprudência interamericana sobre leis de anistia em relação aos desaparecimentos forçados e às execuções extrajudiciais, com a consequente obrigação dos Estados de assegurar o conhecimento da verdade, bem como de investigar, processar e punir graves violações de direitos humanos".

${ }^{11}$ Caso Gelman versus Uruguai, Judgment of 24 February 2011.

REDESG / Revista Direitos Emergentes na Sociedade Global - www.ufsm.br/redesg v. 3, n. 1, jan.jun/2014
} 
Desaparecimento Forçado de Pessoas, não podendo impedir ou obstar a investigação dos fatos, a identificação e eventual sanção dos responsáveis por graves violações a direitos humanos.

\section{3) Violações que refletem desafios acerca do fortalecimento de instituições e da consolidação do Estado de Direito (rule of law)}

Esta terceira categoria de casos remete ao desafio do fortalecimento de instituições e da consolidação do rule of law, particularmente no que se refere ao acesso à justiça, proteção judicial e fortalecimento e independência do Poder Judiciário.

Destaca-se o caso do Tribunal Constitucional contra o Peru $(2001)^{12}$, envolvendo a destituição de juízes, em que a Corte reconheceu necessário garantir a independência de qualquer juiz em um Estado de Direito, especialmente em Cortes constitucionais, o que demanda: a) um adequado processo de nomeação; b) um mandato com prazo certo; e c) garantias contra pressões externas.

Tal decisão contribuiu decisivamente para o fortalecimento de instituições nacionais e para a consolidação do Estado de Direito.

\section{4) Violações de direitos de grupos vulneráveis}

Esta quarta categoria de casos atém-se a decisões que afirmam a proteção de direitos de grupos socialmente vulneráveis, como os povos indígenas, as crianças, os migrantes, os presos, dentre outros.

Quanto aos direitos dos povos indígenas, destaca-se o relevante caso da comunidade indígena Mayagna Awas Tingni contra a Nicarágua (2001) ${ }^{13}$, em que a Corte reconheceu o direitos dos povos indígenas à propriedade coletiva da terra, como uma tradição comunitária, e como um direito fundamental e básico à sua cultura, à sua vida espiritual, à sua integridade e à sua sobrevivência econômica. Acrescentou que para os povos indígenas a relação com a terra não é somente uma questão de possessão e produção, mas um elemento material e espiritual de que devem gozar plenamente, inclusive para preservar seu legado cultural e transmiti-lo às gerações futuras.

\footnotetext{
${ }_{12}$ Aguirre Roca and others vs. Peru case (Constitutional Court Case). Judgment of 31 January 2001. ${ }^{13}$ Mayagna (Sumo) Awas Tingni Community vs. Nicaragua, Inter-American Court, 2001, Ser. C, No. 79.

REDESG / Revista Direitos Emergentes na Sociedade Global - www.ufsm.br/redesg v. 3, n. 1, jan.jun/2014
} 
Em outro caso - caso da comunidade indígena Yakye Axa contra o Paraguai $(2005)^{14}--$, a Corte sustentou que os povos indígenas têm direito a medidas específicas que garantam o acesso aos serviços de saúde, que devem ser apropriados sob a perspectiva cultural, incluindo cuidados preventivos, práticas curativas e medicinas tradicionais. Adicionou que para os povos indígenas a saúde apresenta uma dimensão coletiva, sendo que a ruptura de sua relação simbiótica com a terra exerce um efeito prejudicial sobre a saúde destas populações.

No caso da comunidade indígena Xákmok Kásek v. Paraguai ${ }^{15}$, a Corte Interamericana condenou o Estado do Paraguai pela afronta aos direitos à vida, à propriedade comunitária e à proteção judicial (artigos $4^{\circ}, 21$ e 25 da Convenção Americana, respectivamente), dentre outros direitos, em face da não garantia do direito de propriedade ancestral à aludida comunidade indígena, o que estaria a afetar seu direito à identidade cultural. Ao motivar a sentença, destacou que os conceitos tradicionais de propriedade privada e de possessão não se aplicam às comunidades indígenas, pelo significado coletivo da terra, eis que a relação de pertença não se centra no indivíduo, senão no grupo e na comunidade. Acrescentou que o direito à propriedade coletiva estaria ainda a merecer igual proteção pelo artigo 21 da Convenção (concernente ao direito `a propriedade privada). Afirmou o dever do Estado em assegurar especial proteção às comunidades indígenas, à luz de suas particularidades próprias, suas características econômicas e sociais e suas especiais vulnerabilidades, considerando o direito consuetudinário, os valores, os usos e os costumes dos povos indígenas, de forma a assegurar-lhes o direito à vida digna, contemplando o acesso à água potável, alimentação, saúde, educação, dentre outros.

No caso dos direitos das crianças, cabe menção ao caso Villagran Morales contra a Guatemala (1999) ${ }^{16}$, em que este Estado foi condenado pela Corte, em virtude da impunidade relativa à morte de 5 meninos de rua, brutalmente torturados e assassinados por 2 policiais nacionais da Guatemala. Dentre as medidas de reparação ordenadas pela Corte estão: o pagamento de indenização pecuniária aos familiares das vítimas; a reforma no ordenamento

\footnotetext{
${ }^{14}$ Yakye Axa Community vs. Paraguay, Inter-American Court, 2005, Ser. C, No. 125.

${ }^{15}$ Corte Interamericana de Direitos Humanos, Caso Comunidad Indígena Xákmok Kásek. vs. Paraguay, Fondo, Reparaciones y Costas. Sentencia de 24 de agosto de 2010 Serie C N. 214. Note-se que, no sistema africano, merece menção um caso emblemático que, ineditamente, em nome do direito ao desenvolvimento, assegurou a proteção de povos indígenas às suas terras. Em 2010, a Comissão Africana dos Direitos Humanos e dos Povos considerou que o modo pelo qual a comunidade Endorois no Kenya foi privada de suas terras tradicionais, tendo negado acesso a recursos, constitui uma violação a direitos humanos, especialmente ao direito ao desenvolvimento.
}

${ }^{16}$ Villagran Morales et al versus Guatemala (The Street Children Case), Inter-American Court, 19 November 1999, Ser. C, No. 63.

REDESG / Revista Direitos Emergentes na Sociedade Global - www.ufsm.br/redesg v. 3, n. 1, jan.jun/2014 
jurídico interno visando à maior proteção dos direitos das crianças e adolescentes guatemaltecos; e a construção de uma escola em memória das das vítimas.

Adicione-se, ainda, as opiniões consultivas sobre a condição jurídica e os direitos humanos das crianças (OC 17, emitida em agosto de 2002, por solicitação da Comissão Interamericana de Direitos Humanos) e sobre a condição jurídica e os direitos de migrantes sem documentos (OC18, emitida em setembro de 2003, por solicitação do México).

Mencione-se, também, o parecer emitido, por solicitação do México (OC16, de 01 de outubro de 1999), em que a Corte considerou violado o direito ao devido processo legal, quando um Estado não notifica um preso estrangeiro de seu direito à assistência consular. Na hipótese, se o preso foi condenado à pena de morte, isso constituiria privação arbitrária do direito à vida. Note-se que o México embasou seu pedido de consulta nos vários casos de presos mexicanos condenados à pena de morte nos Estados Unidos.

Com relação aos direitos das mulheres, destacam-se relevantes decisões do sistema interamericano sobre discriminação e violência contra mulheres, o que fomentou a reforma do Código Civil da Guatemala, a adoção de uma lei de violência doméstica no Chile e no Brasil, dentre outros avanços ${ }^{17}$. No caso González e outras contra o México (caso “Campo Algodonero”), a Corte Interamericana condenou o México em virtude do desaparecimento e morte de mulheres em Ciudad Juarez, sob o argumento de que a omissão estatal estava a contribuir para a cultura da violência e da discriminação contra a mulher. No período de 1993 a 2003, estima-se que de 260 a 370 mulheres tenham sido vítimas de assassinatos, em Ciudad Juarez. A sentença da Corte condenou o Estado do México ao dever de investigar, sob a perspectiva de gênero, as graves violações ocorridas, garantindo direitos e adotando medidas preventivas necessárias de forma a combater a discriminação contra a mulher ${ }^{18}$.

Ineditamente, em 24 de fevereiro de 2012, a Corte Interamericana reconheceu a responsabilidade internacional do Estado do Chile em face do tratamento discriminatório e interferência indevida na vida privada e familiar da vítima Karen Atala devido à sua orientação sexual $^{19}$. 0 caso foi objeto de intenso litígio judicial no Chile, que culminou com a decisão da Corte Suprema de Justiça em determinar a custódia das três filhas ao pai, sob o argumento de

\footnotetext{
${ }^{17} \mathrm{~A}$ respeito, ver caso María Eugenia versus Guatemala e caso Maria da Penha versus Brasil decididos pela Comissão Interamericana.

${ }^{18} \mathrm{Ver}$ sentença de 16 de novembro de 2009. Disponível em: www.corteidh.or.cr/docs/casos/articulos/seriec_205_esp.pdf

${ }_{19}^{19}$ Caso Atala Riffo and daughters vs. Chile, Inter-American Court, 24 February 2012, Series C N.239.

REDESG / Revista Direitos Emergentes na Sociedade Global - www.ufsm.br/redesg v. 3, n. 1, jan.jun/2014
} 
que a Sra. Atala não deveria manter a custódia por conviver com pessoa do mesmo sexo, após o divórcio. No entender unânime da Corte Interamericana, o Chile violou os artigos $1^{\circ}$, parágrafo $1^{\circ}$ e 14 da Convenção Americana, por afrontar o princípio da igualdade e da proibição da discriminação.

\section{5) Violações a direitos sociais}

Nesta quinta categoria de casos emergem decisões da Corte que protegem direitos sociais. Importa reiterar que a Convenção Americana de Direitos Humanos estabelece direitos civis e políticos, contemplando apenas a aplicação progressiva dos direitos sociais (artigo 26). Já o Protocolo de San Salvador, ao dispor sobre direitos econômicos, sociais e culturais, prevê que somente os direitos à educação e à liberdade sindical seriam tuteláveis pelo sistema de petições individuais (artigo 19, parágrafo $6^{\circ}$ ).

À luz de uma interpretação dinâmica e evolutiva, compreendendo a Convenção Americana como um living instrument, no já citado caso Villagran Morales contra a Guatemala ${ }^{20}$, a Corte afirmou que o direito à vida não pode ser concebido restritivamente. Introduziu a visão de que o direito à vida compreende não apenas uma dimensão negativa - o direito a não ser privado da vida arbitrariamente --, mas uma dimensão positiva, que demanda dos Estados medidas positivas apropriadas para proteger o direito à vida digna - o “direito a criar e desenvolver um projeto de vida". Esta interpretação lançou um importante horizonte para proteção dos direitos sociais.

Em outros julgados, a Corte tem endossado o dever jurídico dos Estados de conferir aplicação progressiva aos direitos sociais, com fundamento no artigo 26 da Convenção Americana de Direitos Humanos, especialmente em se tratando de grupos socialmente vulneráveis. No caso niñas Yean y Bosico versus Republica Dominicana, a Corte enfatizou o dever dos Estados no tocante à aplicação progressiva dos direitos sociais, a fim de assegurar o direito à educação, com destaque à especial vulnerabilidade de meninas. Sustentou que: “en relación con el deber de desarrollo progresivo contenido en el artículo 26 de la Convención, el Estado debe prover

\footnotetext{
${ }^{20}$ Villagran Morales et al versus Guatemala (The Street Children Case), Inter-American Court, 19 November 1999, Ser. C, No. 63.

REDESG / Revista Direitos Emergentes na Sociedade Global - www.ufsm.br/redesg v. 3, n. 1, jan.jun/2014
} 
SISTEMA INTERAMERICANO DE DIREITOS HUMANOS: IMPACTO TRANSFORMADOR, DIÁLOGOS JURISDICIONAIS E OS DESAFIOS DA REFORMA

educación primaria gratuita a todos los menores, en un ambiente y condiciones propicias para su pleno desarrollo intelectual. ${ }^{21 "}$

Há, ademais, um conjunto de decisões que consagram a proteção indireta de direitos sociais, mediante a proteção de direitos civis, o que confirma a idéia da indivisibilidade e da interdependência dos direitos humanos.

No caso Albán Cornejo y otros versus Equador ${ }^{22}$ referente à suposta negligência médica em hospital particular -- mulher deu entrada no hospital com quadro de meningite bacteriana e foi medicada, vindo a falecer no dia seguinte, provavelmente em decorrência do medicamento prescrito --, a Corte decidiu o caso com fundamento na proteção ao direito à integridade pessoal e não no direito à saúde. No mesmo sentido, no caso Myrna Mack Chang versus Guatemala ${ }^{23}$, concernente a danos à saúde decorrentes de condições de detenção, uma vez mais a proteção ao direito à saúde deu-se sob o argumento da proteção do direito à integridade física.

Outros casos de proteção indireta de direitos sociais atêm-se à proteção ao direito ao trabalho, tendo como fundamento o direito ao devido processo legal e a proteção judicial. A respeito, destaca-se o caso Baena Ricardo y otros versus Panamá ${ }^{4}$, envolvendo a demissão arbitrária de 270 funcionários públicos que participaram de manifestação (greve). A Corte condenou o Estado do Panamá pela violação da garantia do devido processo legal e proteção judicial, determinando o pagamento de indenização e a reintegração dos 270 trabalhadores. No caso Trabajadores cesados del congreso (Aguado Alfaro y otros) versus Peru' ${ }^{25}$, envolvendo a despedida arbitrária de 257 trabalhadores, a Corte condenou o Estado do Peru também pela afronta ao devido processo legal e proteção judicial. Em ambos os casos, a condenação dos Estados teve como argumento central a violação à garantia do devido processo legal e não a violação ao direito do trabalho.

Um outro caso emblemático é o caso "cinco pensionistas" versus Peru" ${ }^{26}$, envolvendo a modificação do regime de pensão no Peru, em que a Corte condenou o Estado com fundamento

\footnotetext{
${ }^{21}$ Caso de las ninas Yean y Bosico v. Republica Dominicana, Inter-American Court, 08 November 2005, Ser. C, N.130

${ }^{22}$ Albán Cornejo y otros v. Ecuador, Inter-American Court, 22 November 2007, serie C n. 171.

${ }^{23}$ Myrna Mack Chang v. Guatemala, Inter-American Court, 25 November 2003, serie C n. 101.

${ }^{24}$ Baena Ricardo y otros v. Panamá, Inter-American Court, 02 February 2001, serie C n. 72.

25 Caso Trabajadores cesados del congreso (Aguado Alfaro y otros) v. Peru, Inter-American Court, 24 November 2006, serie C n. 158.

${ }^{26}$ Caso “cinco pensionistas" v. Peru, Inter-American Court, 28 February 2003, serie C n. 98.

REDESG / Revista Direitos Emergentes na Sociedade Global - www.ufsm.br/redesg v. 3, n. 1, jan.jun/2014
} 
SISTEMA INTERAMERICANO DE DIREITOS HUMANOS: IMPACTO TRANSFORMADOR, DIÁLOGOS JURISDICIONAIS E OS DESAFIOS DA REFORMA

na violação ao direito de propriedade privada e não com fundamento na afronta ao direito de seguridade social, em face dos danos sofridos pelos 5 pensionistas.

No caso Acevedo Buendia vs. Peru ${ }^{27}$, a Corte reconheceu que os direitos humanos devem ser interpretados sob a perspectiva de sua integralidade e interdependência, a conjugar direitos civis e políticos e direitos econômicos, sociais e culturais, inexistindo hierarquia entre eles e sendo todos direitos exigíveis. Realçou ser a aplicação progressiva dos direitos sociais suscetível de controle e fiscalização pelas instâncias competentes, destacando o dever dos Estados de nãoregressividade em matéria de direitos sociais.

\section{6) Violações a novos direitos da agenda contemporânea}

Finalmente, esta sexta categoria de casos compreende novos direitos da agenda contemporânea, com especial destaque aos direitos reprodutivos.

Em sentença proferida em 28 de novembro de 2012, a Corte Interamericana de Direitos Humanos, no caso Artavia Murillo e outros contra a Costa Rica ${ }^{28}$, enfrentou, de forma inédita, a temática da fecundação "in vitro" sob a ótica dos direitos humanos. 0 caso foi submetido pela Comissão Interamericana, sob o argumento de que a proibição geral e absoluta de praticar a “fecundação in vitro" na Costa Rica desde 2000 estaria a implicar violação a direitos humanos. Com efeito, por decisão da Sala Constitucional da Corte Suprema de Justiça de 15 de março de 2000, a prática da fertilização in vitro atentaria claramente contra a vida e a dignidade do ser humano. Todavia, no entender da Comissão, tal proibição estaria a constituir uma ingerência arbitrária com relação aos direitos à vida privada e familiar, bem como ao direito de formar uma família. A proibição estaria ainda a afetar o direito de igualdade das vítimas, eis que o Estado estaria a impedir o acesso a tratamento que permitiria superar uma situação de desvantagem relativamente a ter filhas e filhos biológicos, com impacto desproporcional nas mulheres. 0 argumento da Comissão é de que a proibição da fertilização in vitro afrontaria os direitos à vida privada e familiar; à integridade pessoal; à saúde sexual e reprodutiva; bem como o direito de gozar dos benefícios do progresso científico e tecnológico e o princípio da não discriminação.

${ }^{27}$ Caso Acevedo Buendía y otros (“Cesantes y Jubilados de la Contraloría”) contra o Peru, sentença prolatada em 01 de julho de 2009.

${ }_{28}$ Caso Artavia Murillo e outros ("fecundación in vitro") vs. Costa Rica, Corte Interamericana de Direitos Humanos, sentença proferida em 28 de novembro de 2012.

REDESG / Revista Direitos Emergentes na Sociedade Global - www.ufsm.br/redesg v. 3, n. 1, jan.jun/2014 
A partir de uma interpretação sistemática e histórica, com destaque à normatividade e à jurisprudência dos sistemas universal, europeu e africano, concluiu a Corte Interamericana não ser possível sustentar que o embrião possa ser considerado pessoa. Recorrendo a uma interpretação evolutiva, a Corte observou que o procedimento da fertilização in vitro não existia quando a Convenção foi elaborada, conferindo especial relevância ao Direito Comparado, por meio do diálogo com a experiência jurídica latino-americana e de outros países, como os EUA e a Alemanha, a respeito da matéria. Concluiu que ter filhos biológicos, por meio de técnica de reprodução assistida, decorre dos direitos à integridade pessoal, liberdade e vida privada e familiar. Argumentou que o direito absoluto à vida do embrião -- como base para restringir direitos - não encontra respaldo na Convenção Americana. Condenou, assim, a Costa Rica por violação aos artigos $5^{\circ}$, parágrafo $1^{\circ}, 7^{\circ}, 11$, parágrafo $2^{\circ}$ e 17 , parágrafo $2^{\circ}$ da Convenção Americana, determinando ao Estado adotar com a maior celeridade possível medidas apropriadas para que fique sem efeito a proibição de praticar a fertilização “in vitro”, assegurando às pessoas a possibilidade de valer-se deste procedimento sem impedimentos. Determinou também ao Estado a implementação da fertilização “in vitro", tornando disponíveis os programas e os tratamentos de infertilidade, com base no princípio da não discriminação. Adicionou o dever do Estado de proporcionar às vítimas atendimento psicológico de forma imediata, fomentando, ademais, programas e cursos de educação e capacitação em direitos humanos, no campo dos direitos reprodutivos, sobretudo aos funcionários judiciais.

Ainda no campo dos direitos reprodutivos, em 29 de maio de 2013, ineditamente, a Corte concedeu medidas provisórias em face de El Salvador ${ }^{29}$, em conformidade com os artigos 63.2 da Convenção Americana de Direitos Humanos e 27 do Regulamento da Corte, em caso envolvendo interrupção de gravidez em virtude de anencefalia fetal. Na hipótese, a Senhora "B" 30 encontrava-se na $26^{\mathrm{a}}$ de gravidez de um feto anencefálico, portador de anomalia incompatível com a vida extra-uterina. A Senhora “ $B$ ” apresentava enfermidade materna grave com risco de morte materna.

A Corte determinou ao Estado de El Salvador a concessão de medidas necessárias para proteger a vida, a integridade pessoal e a saúde da Senhora “B”, considerando o urgente e

\footnotetext{
${ }^{29}$ Medidas provisórias em face do Estado de El Salvador, Corte Interamericana de Direitos Humanos, 29 de maio de 2013.

30 Por solicitação da Comissão Interamericana, em respeito à identidade e à privacidade da vítima, a mesma é identificada como Senhora "B".
} 
iminente risco de dano irreparável. Endossou a necessidade do Estado de El Salvador de adotar e garantir, com urgência, todas as medidas que sejam necessárias e efetivas para que a equipe médica responsável pela Senhora “B” possa adotar, sem qualquer interferência, as medidas médicas para assegurar a devida proteção aos direitos consagrados nos artigos $4^{\circ}$ e $5^{\circ}$ da Convenção Americana, evitando, assim, danos que possam ser irreparáveis aos direitos à vida, à integridade pessoal e à saúde da Senhora "B".

\section{EMPODERAMENTO DO SISTEMA INTERAMERICANO MEDIANTE A EFETIVIDADE DO DIÁLOGO JURISDICIONAL E CRESCENTE LEGITIMAÇÃO SOCIAL}

O sistema interamericano é capaz de revelar as peculiariedades e especificidades das lutas emancipatórias por direitos e por justiça na região latino-americana. 0 sistema apresenta uma particular institucionalidade marcada pelo protagonismo de diversos atores, em um palco em que interagem Estados, vítimas, organizações da sociedade civil nacionais e internacionais, a Comissão e a Corte Interamericana no âmbito da Organização dos Estados Americanos.

Neste contexto, o sistema interamericano gradativamente se empodera, mediante diálogos a permitir o fortalecimento dos direitos humanos em um sistema multinível. É sob esta perspectiva multinível que emergem quatro vertentes do diálogo jurisdicional, a compreender o diálogo com o sistema global (mediante a incorporação de parâmetros protetivos de direitos humanos); o diálogo com os sistemas regionais (a envolver a "europeicização" do sistema interamericano e a "interamericanização" do sistema europeu); o diálogo com os sistemas nacionais (a abranger o controle da convencionalidade); e o diálogo com a sociedade civil (a emprestar ao sistema interamericano crescente legitimação social).

No que se refere ao diálogo com o sistema global, constata-se a incorporação crescente de parâmetros protetivos de direitos humanos do sistema global (ONU) nas sentenças proferidas pela Corte Interamericana, com realce à "soft jurisprudence" fomentada pelos treaties bodies. A título ilustrativo, destaque-se menção à Declaração da ONU sobre Povos Indígenas de 2007, bem como à jurisprudência do Comitê Geral n. 17/2005 do Comitê da ONU sobre Direitos Econômicos, Sociais e Culturais, na sentença proferida pela Corte Interamericana no caso Pueblo Indígena Kichwa de Sarayaku vs. Equador, de 27 de junho de 2012. Outro exemplo atém-se à sentença do REDESG / Revista Direitos Emergentes na Sociedade Global - www.ufsm.br/redesg v. 3, n. 1, jan.jun/2014 
SISTEMA INTERAMERICANO DE DIREITOS HUMANOS: IMPACTO TRANSFORMADOR, DIÁLOGOS JURISDICIONAIS E OS DESAFIOS DA REFORMA

caso Atala Riffo y ninas vs. Chile, de 24 de fevereiro de 2012, em que a Corte Interamericana incorpora a jurisprudência dos Comitês da ONU de Direitos Humanos, de Direitos Econômicos, Sociais e Culturais, contra a Tortura, sobre a Eliminação da Discriminação contra a Mulher e sobre a Eliminação de todas as formas de Discriminação Racial, tecendo, ainda, menção à Declaração da ONU sobre Orientação Sexual e Identidade de Gênero, de 2008. Na sentença do caso Geman vs. Uruguai, de 24 de fevereiro de 2012, a Corte menciona a Convenção da ONU para a Proteção de todas as Pessoas contra o Desaparecimento Forçado de 2006, bem como a Convenção sobre os Direitos da Criança e a jurisprudência do respectivo Comitê. Também na sentença do caso Artavia Murillo e outros (fecundacion “in vitro") vs. Costa Rica, em 28 de novembro de 2012, a Corte Interamericana argumentou com base na interpretação histórica e sistemática, tecendo diálogo com o sistema universal de direitos humanos, em especial com a Declaração Universal de 1948, o Pacto Internacional de Direitos Civis e Políticos, a Convenção sobre a Eliminação de todas as formas de Discriminação contra a Mulher e a Convenção sobre os Direitos da Criança.

Quanto ao diálogo com os sistemas regionais, faz-se cada vez mais intenso os processos de "interamericanização" do sistema europeu e de "europeicização" do sistema interamericano.

A inclusão dos países do Leste Europeu no sistema europeu, com sua agenda própria de violações, está a deflagrar a crescente abertura da Corte Européia à jurisprudência interamericana relativa a graves violações de direitos perpetradas por regimes autoritários, envolvendo a prática de tortura, execução sumária e desaparecimento forçado de pessoas. Como demonstra relatório produzido pelo Conselho da Europa, ao analisar 25 (vinte e cinco) sentenças proferidas pela Corte Européia, há expressiva referência à jurisprudência da Corte Interamericana, sobretudo em matéria de desaparecimento forçado, combate à impunidade e justiça de transição, com destaque às sentenças dos casos Velásquez Rodrigues vs. Honduras, Godinez Gruz vs. Honduras, Loyaza Tamayo vs. Peru e Barrios Altos vs. Peru, na jurisprudência da Corte Européia. Também foram localizados julgados da Corte Européia concernentes a direitos sociais, com menção às sentenças da Corte Interamericana nos casos Acevedo Buendia vs. Peru e Cinco Pensionistas vs. Peru ${ }^{31}$.

Por sua vez, a Corte Interamericana ao enfrentar novos temas de direitos humanos emergentes na agenda contemporânea - passa a aludir aos precedentes da Corte Européia, como

\footnotetext{
${ }^{31}$ A respeito, ver Council of Europe. Research Report, References to the Inter-American Court of Human Rights in the case-law of the European Court of Human Rights. 2012.

REDESG / Revista Direitos Emergentes na Sociedade Global - www.ufsm.br/redesg v. 3, n. 1, jan.jun/2014
} 
SISTEMA INTERAMERICANO DE DIREITOS HUMANOS: IMPACTO TRANSFORMADOR, DIÁLOGOS JURISDICIONAIS E OS DESAFIOS DA REFORMA

bem ilustra o leading case Karen Atala y hijas vs. Chile, decidido em 24 de fevereiro de $2012^{32}$. Trata-se de inédita e emblemática sentença concernente à proibição da discriminação fundada em orientação sexual, em que a Corte Interamericana no campo argumentativo alude ao relevante repertório jurisprudencial firmado pela Corte Européia em caso similar ${ }^{33}$. De igual modo, no caso Artavia Murillo e outros vs. Costa Rica, em sentença de 28 de novembro de 2012, a Corte, ao enfocar a temática da fertilização "in vitro", em sua argumentação adotou precedentes da Corte Européia de Direitos Humanos a respeito do alcance do direito à vida. Também no caso Puelo Também no caso Puelo Indígena Kichwa de Sarayaku vs. Equador, de 27 de junho de 2012, a Corte Interamericana vale-se de precedente da Corte Européia em matéria de direito à identidade cultural, endossando o entendimento de que o direito à identidade cultural deve ser respeitado em sociedades multiculturais, pluralistas e democráticas. $\mathrm{Na}$ sentença do caso Gelman vs. Uruguai, de 24 de fevereiro de 2012, a Corte Interamericana alude à jurisprudência da Corte Européia em casos contra a Turquia e a Hungria.

A respeito do diálogo com os sistemas nacionais consolida-se o chamado "controle de convencionalidade". Tal controle é reflexo de um novo paradigma a nortear a cultura jurídica latino-americana na atualidade: da hermética pirâmide centrada no State approach à permeabilidade do trapézio centrado no Human rights approach.

Isto é, aos parâmetros constitucionais somam-se os parâmetros convencionais, na composição de um trapézio juridico aberto ao diálogo, aos empréstimos e à interdisciplinariedade, a resignificar o fenômeno jurídico sob a inspiração do human rights approach.

No caso latino-americano, o processo de democratização na região, deflagrado na década de 80 , é que propiciou a incorporação de importantes instrumentos internacionais de proteção dos direitos humanos pelos Estados latino-americanos. Hoje constata-se que os países

\footnotetext{
${ }_{32}$ Caso Atala Riffo and daughters vs. Chile, Inter-American Court, 24 February 2012, Series C N.239.

${ }^{33} \mathrm{Com}$ efeito, a Corte Interamericana recorreu ao caso Salgueiro da Silva Mouta vs. Portugal, sustentando que: "Respecto a la inclusión de la orientación sexual como categoria de discriminación prohibido, el Tribunal Europeo de Derechos Humanos há señalado que la orientación sexual es "outra condición" mencionada em el artículo 14 del Convenio Europeu para la Protección de los Derechos Humanos e de las Libertades Fundamentales, el cual prohíbe tratos discriminatórios. En particular, em el caso Salgueira da Silva Mouta vs. Portugal, el Tribunal Europeo concluyo que la orientación sexual es un concepto que se encuentra cubierto por el articulo 14 del Convenio Europeu. Además, reiteró que el listado de categorias que se realiza em dicho artículo es ilustrativa y no exhaustiva." (Caso Atala Riffo and daughters vs. Chile, Inter-American Court, 24 February 2012, Series C N.239).
}

REDESG / Revista Direitos Emergentes na Sociedade Global - www.ufsm.br/redesg v. 3, n. 1, jan.jun/2014 
SISTEMA INTERAMERICANO DE DIREITOS HUMANOS: IMPACTO TRANSFORMADOR, DIÁLOGOS JURISDICIONAIS E OS DESAFIOS DA REFORMA

latino-americanos subscreveram os principais tratados de direitos humanos adotados pela ONU e pela OEA.

De um lado, despontam Constituições latino-americanas com cláusulas constitucionais abertas, com destaque à hierarquia especial dos tratados de direitos humanos, à sua incorporação automática e às regras interpretativas alicerçadas no princípio pro persona.

Com efeito, as Constituições latino-americanas estabelecem cláusulas constitucionais abertas, que permitem a integração entre a ordem constitucional e a ordem internacional, especialmente no campo dos direitos humanos, ampliando e expandindo o bloco de constitucionalidade. Ao processo de constitucionalização do Direito Internacional conjuga-se o processo de internacionalização do Direito Constitucional. A título exemplificativo, a Constituição da Argentina, após a reforma constitucional de 1994, dispõe, no artigo 75, inciso 22, que, enquanto os tratados em geral têm hierarquia infra-constitucional, mas supra-legal, os tratados de proteção dos direitos humanos têm hierarquia constitucional, complementando os direitos e garantias constitucionalmente reconhecidos. A Constituição Brasileira de 1988, no artigo $5^{\circ}$, parágrafo $2^{\circ}$, consagra que os direitos e garantias expressos na Constituição não excluem os direitos decorrentes dos princípios e do regime a ela aplicável e os direitos enunciados em tratados internacionais ratificados pelo Brasil, permitindo, assim, a expansão do bloco de constitucionalidade. A então Constituição do Peru de 1979, no mesmo sentido, determinava, no artigo 105, que os preceitos contidos nos tratados de direitos humanos têm hierarquia constitucional e não podem ser modificados senão pelo procedimento que rege a reforma da própria Constituição. Já a atual Constituição do Peru de 1993 consagra que os direitos constitucionalmente reconhecidos devem ser interpretados em conformidade com a Declaração Universal de Direitos Humanos e com os tratados de direitos humanos ratificados pelo Peru. Decisão proferida em 2005 pelo Tribunal Constitucional do Peru endossou a hierarquia constitucional dos tratados internacionais de proteção dos direitos humanos, adicionando que os direitos humanos enunciados nos tratados conformam a ordem jurídica e vinculam os poderes públicos. A Constituição da Colômbia de 1991, reformada em 1997, confere, no artigo 93, hierarquia especial aos tratados de direitos humanos, determinando que estes prevalecem na ordem interna e que os direitos humanos constitucionalmente consagrados serão interpretados em conformidade com os tratados de direitos humanos ratificados pelo país. Também a Constituição do Chile de 1980, em decorrência da reforma constitucional de 1989, passou a consagrar o dever dos órgãos do Estado de respeitar e promover os direitos garantidos pelos 
tratados internacionais ratificados por aquele país. Acrescente-se a Constituição da Bolívia de 2009, ao estabelecer que os direitos e deveres reconhecidos constitucionalmente serão interpretados em conformidade com os tratados de direitos humanos ratificados pela Bolívia, que prevalecerão em relação à própria Constituição se enunciarem direitos mais favoráveis (artigos 13, IV e 256). Na mesma direção, destaca-se a Constituição do Equador de 2008, ao consagrar que a Constituição e os tratados de direitos humanos ratificados pelo Estado que reconheçam direitos mais favoráveis aos previstos pela Constituição têm prevalência em relação a qualquer outra norma jurídica ou ato do Poder Público (artigo 424), adicionando que serão aplicados os princípios pro ser humano, de não restrição de direitos, de aplicabilidade direta e de cláusula constitucional aberta (artigo 416). A Constituição do México, com a reforma de junho de 2011, passou a contemplar a hierarquia constitucional dos tratados de direitos humanos e a regra interpretativa fundada no princípio pro persona.

Por outro lado, o sistema interamericano revela permeabilidade e abertura ao diálogo mediante as regras interpretativas do artigo 29 da Convenção Americana, em especial as que asseguram o princípio da prevalência da norma mais benéfica, mais favorável e mais protetiva à vítima. Ressalte-se que os tratados de direitos humanos fixam parâmetros protetivos mínimos, constituindo um piso mínimo de proteção e não um teto protetivo máximo. Daí a hermenêutica dos tratados de direitos humanos endossar o princípio pro ser humano. Às regras interpretativas consagradas no artigo 29 da Convenção Americana, somem-se os tratados de direitos humanos do sistema global - que, por sua vez, também enunciam o princípio pro persona fundado na prevalência da norma mais benéfica, como ilustram o artigo 23 da Convenção sobre a Eliminação da Discriminação contra a Mulher, o artigo 41 da Convenção sobre os Direitos da Criança, o artigo 16, parágrafo $2^{\circ}$ da Convenção contra a Tortura e o artigo $4^{\circ}$, parágrafo $4^{\circ}$ da Convenção sobre os Direitos das Pessoas com Deficiência.

Claúsulas de abertura constitucional e o princípio pro ser humano inspirador dos tratados de direitos humanos compõem os dois vértices -- nacional e internacional -- a fomentar o diálogo em matéria de direitos humanos. No sistema interamericano este diálogo é caracterizado pelo fenômeno do "controle da convencionalidade", na sua forma difusa e concentrada.

Como enfatiza a Corte Interamericana: "Quando um Estado ratifica um tratado internacional como a Convenção Americana, seus juízes, como parte do aparato do Estado, também estão submetidos a ela, o que lhes obriga a zelar para que os efeitos dos dispositivos da Convenção não se vejam mitigados pela aplicação de leis contrárias a seu objeto, e que desde o 
SISTEMA INTERAMERICANO DE DIREITOS HUMANOS: IMPACTO TRANSFORMADOR, DIÁLOGOS JURISDICIONAIS E OS DESAFIOS DA REFORMA

início carecem de efeitos jurídicos. (...) o poder Judiciário deve exercer uma espécie de "controle da convencionalidade das leis. Entre as normas jurídicas internas que aplicam nos casos concretos e a Convenção Americana sobre Direitos Humanos. Nesta tarefa, o Poder Judiciário deve ter em conta não somente o tratado, mas também a interpretação que do mesmo tem feito a Corte Interamericana, intérprete última da Convenção Americana".34

Como sustenta Eduardo Ferrer Mac-Gregor35, o juiz nacional agora é também juiz interamericano, tendo como mandato exercer o controle de convencionalidade na modalidade difusa. Cortes nacionais exercem o controle da convencionalidade na esfera doméstica, mediante a incorporação da normatividade, principiologia e jurisprudência protetiva internacional em matéria de direitos humanos no contexto latino-americano. Frise-se: quando um Estado ratifica um tratado, todos os órgãos do poder estatal a ele se vinculam, compromentendo-se a cumpri-lo de boa-fé.

A Corte Interamericana exerce o controle da convencionalidade na modalidade concentrada, tendo a última palavra sobre a interpretação da Convenção Americana. Na realização do controle de convencionalidade, a Corte Interamericana guia-se pelo princípio pro persona, conferindo prevalência à norma mais benéfica, destacando, em diversas sentenças, decisões judiciais proferidas pelas Cortes constitucionais latino-americanas, bem como menção a dispositivos das Constituições latino-americanas, como podem revelar os casos Pueblo Indígena Kichwa de Sarayaku vs. Equador (sentença proferida em 27 de junho de 2012), Atala Riffo y ninas vs. Chile (sentença proferida em 24 de fevereiro de 2012) e Gelman vs. Uruguai (sentença proferida em 24 de fevereiro de 2012). 36

\footnotetext{
${ }^{34}$ Ver caso Almonacid Arellano and others vs. Chile. Judgment of 26 September 2006.

${ }^{35}$ Eduardo Ferrer Mac-Gregor, Interpretación conforme y control difuso de convencionalidad: El Nuevo paradigma para el juez mexicano, In: Armin von Bogdandy, Flavia Piovesan e Mariela Morales Antoniazzi, Estudos Avançados de Direitos Humanos - Democracia e Integração Jurídica: Emergência de um novo Direito Público, São Paulo, ed. Campus Elsevier, 2013, p.627-705.

${ }^{36}$ A título ilustrativo, cabe menção à sentença proferida pela Corte Interamericana no caso Pueblo Indígena Kichwa de Sarayaku vs. Equador, de 27 de junho de 2012, em que a Corte incorpora precedentes judiciais em matéria indígena da Corte Constitucional Colombiana (sentencia C-169/01), no que se refere ao direito à consulta prévia dos povos indígenas, bem como ao pluralismo. Empresta ainda destaque às Constituições da Argentina, da Bolívia, do Brasil, do Peru e do Chile. Outro exemplo atém-se à sentença do caso Atala Riffo y ninas vs. Chile, de 24 de fevereiro de 2012, em que a Corte Interamericana faz alusão à jurisprudência da Suprema Corte de Justicia de la Nación do México, na Al 2/2010, concernente à proibição da discriminação por orientação sexual. No caso Guelman vs. Uruguai, por sua vez, a Corte destaca a jurisprudência da Venezuela, do México, do Chile, da Argentina e da Bolivia reconhecendo a natureza pluriofensiva e permanente do delito de desaparecimento forçado, bem como a jurisprudência latino-americana invalidando leis de anistia.
} 
Por fim, adicione-se o profícuo diálogo do sistema interamericano com a sociedade civil, o que the confere gradativa legitimação social e crescente empoderamento. 0 sistema enfrenta o paradoxo de sua origem - nasceu em um ambiente marcado pelo arbítrio de regimes autoritários com a expectativa estatal de seu reduzido impacto - e passa a ganhar credibilidade, confiabilidade e elevado impacto. A força motriz do sistema interamericano tem sido a sociedade civil organizada por meio de um transnational network, a empreender exitosos litígios estratégicos.

$\mathrm{Na}$ experiência brasileira, por exemplo, $100 \%$ dos casos submetidos à Comissão Interamericana foram fruto de uma articulação a reunir vítimas e organizações não governamentais locais e internacionais37, com intenso protagonismo na seleção de um caso paradigmático, na litigância do mesmo (aliando estratégias jurídicas e políticas) e na implementação doméstica de eventuais ganhos internacionais.

Transita-se, deste modo, ao enfoque dos desafios centrais ao sistema interamericano, à luz da agenda do processo de reforma, com vistas à pavimentação de um "ius commune latinoamericano en derechos humanos".

\section{DESAFIOS DO SISTEMA INTERAMERICANO, AGENDA DE REFORMAS E A PAVIMENTAÇÃO DE UM “IUS COMMUNE LATINO-AMERICANO EN DERECHOS HUMANOS"}

A partir da análise do impacto da jurisprudência da Corte Interamericana de Direitos Humanos na região latino-americana, sob a perspectiva de um sistema multinível e dialógico a envolver as esferas global, regional e local, tendo ainda como força impulsionadora o ativismo transnacional da sociedade civil, vislumbra-se a pavimentação de um ius commune latinoamericano em direitos humanos.

É à luz desta dinâmica que emergem três desafios centrais à pavimentação dos ius commune latino-americano em direitos humanos:

\footnotetext{
${ }^{37}$ Flávia Piovesan, Direitos Humanos e o Direito Constitucional Internacional, $14^{\mathrm{a}}$ ed. revista e atualizada, ed. Saraiva, São Paulo, 2013.

REDESG / Revista Direitos Emergentes na Sociedade Global - www.ufsm.br/redesg v. 3, n. 1, jan.jun/2014
} 
i) Fomentar uma cultura jurídica inspirada em novos paradigmas jurídicos e na emergência de um novo Direito Público: estatalidade aberta, diálogo jurisdicional e prevalência da dignidade humana em um sistema multinivel ${ }^{38}$

A existência de cláusulas constitucionais abertas a propiciar o diálogo entre as ordens jurídicas local, regional e global, por si só, não assegura a efetividade do diálogo jurisdicional em direitos humanos. Se, de um lado, constata-se o maior refinamento das cláusulas de abertura constitucional - a contemplar a hierarquia, a incorporação e as regras interpretativas de instrumentos internacionais de direitos humanos - por outro lado, esta tendência latinoamericana não é suficiente para o êxito do diálogo jurisdicional em matéria de direitos humanos. Isto porque interpretações jurídicas reducionistas e restritivas das ordens constitucionais podem comprometer o avanço e a potencialidade de cláusulas abertas.

Daí a necessidade de fomentar uma doutrina e uma jurisprudência emancipatórias no campo dos direitos humanos inspiradas na prevalência da dignidade humana ${ }^{39}$ e na emergência de um novo Direito Público marcado pela estatalidade aberta em um sistema jurídico multinível. A formação de uma nova cultura jurídica, baseada em uma nova racionalidade e ideologia, surge como medida imperativa à afirmação do ius commune latino-americano em direitos humanos.

ii) Fortalecer o sistema interamericano de proteção de direitos humanos: universalidade, institucionalidade, independência, sustentabilidade e efetividade

Outro importante desafio à consolidação de um ius commune latino-americano em direitos humanos atém-se ao aprimoramento do sistema interamericano, considerando a agenda de reformas do sistema ${ }^{40}$.

\footnotetext{
${ }^{38}$ Ver Armin von Bogdandy, Flavia Piovesan e Mariela Morales Antoniazzi (coord.), Estudos Avançados de Direitos Humanos -- democracia e integração jurídica: emergência de um novo Direito Público, São Paulo, Campus Elsevier, 2013.

${ }^{39}$ Para Habermas, o princípio da dignidade humana é a fonte moral da qual os direitos fundamentais extraem seu conteúdo. Adiciona Habermas: "The appeal to human rights feeds off the outrage of the humiliated at the violation of their human dignity (...) The origin of human rights has always been resistance to despotism, oppression and humiliation (...)". (Jurgen Habermas, The Crisis of the European Union: A Response, Cambridge, Polity Press, 2012, p.75).

${ }^{40}$ No debate acerca da reforma do sistema interamericano, há controvertidas propostas formuladas por Estados visando à restrição do poder da Comissão Interamericana em conceder medidas cautelares e à limitação de relatorias especiais, como a relatoria especial sobre a liberdade de expressão e acesso à REDESG / Revista Direitos Emergentes na Sociedade Global - www.ufsm.br/redesg v. 3, n. 1, jan.jun/2014
} 
SISTEMA INTERAMERICANO DE DIREITOS HUMANOS: IMPACTO TRANSFORMADOR, DIÁLOGOS JURISDICIONAIS E OS DESAFIOS DA REFORMA

Com relação à universalidade do sistema interamericano há se expandir o universo de Estados-partes da Convenção Americana (que contava com 25 Estados-partes em 2012) e sobretudo do Protocolo de San Salvador em matéria de direitos econômicos, sociais e culturais (que contava apenas com 14 Estados-partes em 2012). Outra medida essencial é ampliar o grau de reconhecimento da jurisdição da Corte Interamericana de Direitos Humanos, a contar com o aceite de 22 Estados, em 2012. Observa-se que a OEA compreende 34 Estados membros.

Outra relevante medida é assegurar a elevada independência e autonomia dos membros integrantes da Comissão e da Corte Interamericana, que devem atuar a título pessoal e não governamental. Faz-se necessário densificar a participação da sociedade civil no monitoramento do processo de indicação de tais membros, doando-lhe maior publicidade, transparência e accountability.

Também fundamental é fortalecer a efetividade do sistema interamericano, seja no que se refere à supervisão das decisões da Corte e da Comissão. ${ }^{41}$ Diversamente do sistema europeu, no sistema interamericano são seus próprios órgãos que realizam o follow up das decisões que eles próprios proferem. Isto porque a Convenção Americana não estabelece mecanismo específico para supervisionar o cumprimento das decisões da Comissão ou da Corte, embora a Assembléia Geral da OEA tenha o mandato genérico a este respeito, nos termos do artigo 65 da Convenção Americana ${ }^{42}$. Na avaliação de Antônio Augusto Cançado Trindade: “(...) a Corte Interamericana tem atualmente uma especial preocupação quanto ao cumprimento de suas sentenças. Os Estados, em geral, cumprem as reparações que se referem a indenizações de caráter pecuniário, mas o mesmo não ocorre necessariamente com as reparações de caráter não pecuniário, em especial as que se referem às investigações efetivas dos fatos que originaram tais violações, bem como à identificação e sanção dos responsáveis, - imprescindíveis para por fim à impunidade (e suas consequências negativas para o tecido social como um todo). (...)

informação. Para um enfoque crítico destas propostas, ver Deisy Ventura, Flávia Piovesan e Juana Kweitel, Sistema Interamericano sob Forte Ataque, Folha de São Paulo, p. A3, 07 de agosto de 2012.

${ }^{41}$ No sistema europeu, a título exemplificativo, o Comitê de Ministros (órgão político) tem a função de supervisionar a execução das decisões da Corte Européia, atuando coletivamente em nome do Conselho da Europa. Para uma análise comparativa dos sistemas regionais, ver Flávia Piovesan, Direitos Humanos $e$ Justiça Internacional: Um estudo comparativo dos sistemas regionais europeu, interamericano e africano, São Paulo, $3^{\mathrm{a}}$ edição revista, ampliada e atualizada, ed. Saraiva, 2012.

42 De acordo com o artigo 65 da Convenção: “A Corte submeterá à consideração da Assembléia Geral da OEA, em cada período ordinário de sessões, um relatório sobre as suas atividades no ano anterior. De maneira especial, e com as recomendações pertinentes, indicará os casos em que um Estado não tenha dado cumprimento a suas sentenças". 
SISTEMA INTERAMERICANO DE DIREITOS HUMANOS: IMPACTO TRANSFORMADOR, DIÁLOGOS JURISDICIONAIS E OS DESAFIOS DA REFORMA

Atualmente, dada a carência institucional do sistema interamericano de proteção dos direitos humanos nesta área específica, a Corte Interamericana vem exercendo motu propio a supervisão da execução de suas sentenças, dedicando-lhe um ou dois dias de cada período de sessões. Mas a supervisão - como exercício de garantia coletiva - da fiel execução das sentenças e decisões da Corte é uma tarefa que recai sobre o conjunto dos Estados-partes da Convenção ${ }^{43}$."

Ademais, as decisões internacionais em matéria de direitos humanos devem produzir eficácia jurídica direta, imediata e obrigatória no âmbito do ordenamento jurídico interno, cabendo aos Estados sua fiel execução e cumprimento, em conformidade com o princípio da boa fé, que orienta a ordem internacional. Para Antonio Augusto Cançado Trindade: "O futuro do sistema internacional de proteção dos direitos humanos está condicionado aos mecanismos nacionais de implementação." ${ }^{4}$

Outra medida emergencial atém-se à sustentabilidade do sistema interamericano, mediante o funcionamento permanente da Comissão e da Corte, com recursos financeiros ${ }^{45}$, técnicos e administrativos suficientes.

\section{iii) Avançar na proteção dos direitos humanos, da democracia e do Estado de Direito na região}

\footnotetext{
${ }^{43}$ Antônio Augusto Cançado Trindade e Manuel E. Ventura Robles, El Futuro de la Corte Interamericana de Derechos humanos, $2^{\mathrm{a}}$ ed. atualizada e ampliada, San José/Costa Rica, Corte Interamericana de Direitos Humanos e ACNUR, 2004, p.434. Propõe o autor: "Para assegurar o monitoramento contínuo do fiel cumprimento de todas as obrigações convencionais de proteção, em particular das decisões da Corte, deve ser acrescentado ao final do artigo 65 da Convenção Americana, a seguinte frase: "A Assembléia Geral os remeterá ao Conselho Permanente, para estudar a matéria e elaborar um informe, a fim de que a Assembléia Geral delibere a respeito." Deste modo, se supre uma lacuna com relação a um mecanismo, a operar em base permanente (e não apenas uma vez por ano, ante a Assembléia Geral da OEA), para supervisionar a fiel execução, por todos os Estados-partes demandados, das sentenças da Corte". (op. cit. p.91-92)

${ }^{44}$ Antônio Augusto Cançado Trindade e Manuel E. Ventura Robles, El Futuro de la Corte Interamericana de Derechos humanos, $2^{a}$ ed., revista e atualizada, San José/Costa Rica, Corte Interamericana de Direitos Humanos e UNHCR, 2004, p.91.

${ }^{45}$ A título ilustrativo, o orçamento da Corte Européia corresponde aproximadamente a $20 \%$ do orçamento do Conselho da Europa, envolvendo 41 milhões de euros, enquanto que o orçamento conjunto da Comissão e da Corte Interamericana corresponde aproximadamente a 5\% do orçamento da OEA, envolvendo apenas 4 milhões de dólares norte-americanos. Observe-se, ainda, que os $5 \%$ de orçamento da OEA cobre tão somente $55 \%$ das despesas da Comissão e $46 \%$ das despesas da Corte Interamericana.
} 
Finalmente, considerando o contexto latino-americano marcado por acentuada desigualdade social e violência sistêmica, fundamental é avançar na afirmação dos direitos humanos, da democracia e do Estado de Direito na região.

Ao enfrentar os desafios de sociedades pós coloniais latino-americanas -- em que direitos humanos tradicionalmente constituíam uma agenda contra o Estado -- o sistema interamericano empodera-se e com sua força invasiva contribui para o fortalecimento dos direitos humanos, da democracia e do Estado de Direito na região.

O sistema interamericano rompe com o paradoxo de sua origem. Nascido em um contexto regional marcado por regimes ditatoriais - seguramente com a expectativa de reduzido impacto por parte dos então Estados autoritários - o sistema se consolida e se fortalece como ator regional democratizante, provocado por competentes estratégias de litigância da sociedade civil em um transnational network a lhe conferir elevada carga de legitimação social.

Como evidenciado por este artigo, o sistema interamericano permitiu a desestabilização dos regimes ditatoriais; exigiu justiça e o fim da impunidade nas transições democráticas; e agora demanda o fortalecimento das instituições democráticas com o necessário combate às violações de direitos humanos e proteção aos grupos mais vulneráveis. O sistema interamericano tem assim concretizado o potencial emancipatório dos direitos humanos. Como lembra Habermas "the origin of human rights has always been resistance to despotism, oppression and humiliation (...)"

O seu impacto transformador na região -- fruto sobretudo do papel vital da sociedade civil organizada em sua luta por justiça e por direitos - é fomentado pela efetividade do diálogo regional-local em um sistema multinível com abertura e permeabilidade mútuas. De um lado, o sistema interamericano se inspira no princípio pro ser humano, mediante regras convencionais interpretativas baseadas no princípio da norma mais protetiva e favorável à vítima, endossando contemplar parâmetros protetivos mínimos. Por outro lado, as Constituições latino-americanas estabelecem cláusulas de abertura constitucional a propiciar o diálogo em matéria de direitos humanos, concernentes à hierarquia, incorporação e impacto dos tratados de direitos humanos.

No sistema interamericano este diálogo é ainda caracterizado pelo fenômeno do

\footnotetext{
46 Adiciona Habermas: "The appeal to human rights feeds off the outrage of the humiliated at the violation of their human dignity". Para o autor, o princípio da dignidade humana é a fonte moral da qual os Direitos fundamentais extraem seu conteúdo. (Jurgen Habermas, The Crisis of the European Union: $A$ Response, Cambridge, Polity Press, 2012, p.75).
} 
"controle da convencionalidade", na sua forma difusa e concentrada. Constata-se também a crescente abertura da Corte Interamericana ao incorporar em suas decisões a normatividade e a jurisprudência latino-americana em direitos humanos, com alusão a dispositivos de Constituições latino-americanas e à jurisprudência das Cortes Constitucionais latino-americanas. O diálogo jurisdicional se desenvolve em dupla via: movido pelos vértices de cláusulas constitucionais abertas e do princípio pro ser humano.

É neste contexto que o sistema interamericano tem a potencialidade de exercer um extraordinário impacto na pavimentação de um ius commune latino-americano, contribuindo para o fortalecimento dos direitos humanos, da democracia e do Estado de Direito na região mais desigual e violenta do mundo.

\section{REFERÊNCIAS}

ADVISORY OPINION. No. 3/83, of 8 September 1983.

ALBÁN CORNEJO Y OTROS V. ECUADOR. Inter-American Court, 22 November 2007, serie C n. 171.

BUERGENTHAL, Thomas. PASQUALUCCI, Jo M. The Practice and Procedure of the InterAmerican Court on Human Rights, Cambridge, Cambridge University Press, 2003, p.XV.

CORTE INTERAMERICANA DE DIREITOS HUMANOS, Caso Comunidad Indígena Xákmok Kásek. vs. Paraguay, Fondo, Reparaciones y Costas. Sentencia de 24 de agosto de 2010 Serie C N. 214.

CORTE INTERAMERICANA DE DIREITOS HUMANOS. “CINCO PENSIONISTAS” V. PERU. InterAmerican Court, 28 February 2003, serie C n. 98.

CORTE INTERAMERICANA DE DIREITOS HUMANOS. ATALA RIFFO AND DAUGHTERS VS. CHILE. InterAmerican Court, 24 February 2012, Series C N.239.

CORTE INTERAMERICANA DE DIREITOS HUMANOS. BAENA RICARDO Y OTROS V. PANAMÁ. InterAmerican Court, 02 February 2001, serie C n. 72.

CORTE INTERAMERICANA DE DIREITOS HUMANOS. DE LAS NINAS YEAN Y BOSICO V. REPUBLICA DOMINICANA. Inter-American Court, 08 November 2005, Ser. C, N.130

CORTE INTERAMERICANA DE DIREITOS HUMANOS. Mayagna (Sumo) Awas Tingni Community vs. Nicaragua, Inter-American Court, 2001, Ser. C, No. 79. 
CORTE INTERAMERICANA DE DIREITOS HUMANOS. TRABAJADORES CESADOS DEL CONGRESO (AGUADO ALFARO Y OTROS) V. PERU. Inter-American Court, 24 November 2006, serie C n. 158.

CORTE INTERAMERICANA DE DIREITOS HUMANOS. Velasquez Rodriguez Case, Inter-American Court of Human Rights, 1988, Ser. C, No. 4.

CORTE INTERAMERICANA DE DIREITOS HUMANOS. Villagran Morales et al versus Guatemala (The Street Children Case), Inter-American Court, 19 November 1999, Ser. C, No. 63.

CORTE INTERAMERICANA DE DIREITOS HUMANOS. Yakye Axa Community vs. Paraguay, InterAmerican Court, 2005, Ser. C, No. 125.

HABERMAS, Jurgen. The Crisis of the European Union: A Response, Cambridge, Polity Press, 2012, p.75.

LAGOS, Marta. DAMMERT, Lucía. La Seguridad Ciudadana: El problema principal de América Latina, Latinobarómetro, 9 de maio de 2012, p.3.

LATINOBARÓMETRO. Informe 2011, Santiago do Chile, 28 de outubro de 2012.

MAC-GREGOR, EDUARDO FERRER. Interpretación conforme y control difuso de convencionalidad: El Nuevo paradigma para el juez mexicano, In: Armin von Bogdandy, Flavia Piovesan e Mariela Morales Antoniazzi, Estudos Avançados de Direitos Humanos - Democracia e Integração Jurídica: Emergência de um novo Direito Público, São Paulo, ed. Campus Elsevier, 2013.

PIOVESAN Flávia. Direitos Humanos e Justiça Internacional: Um estudo comparativo dos sistemas regionais europeu, interamericano e africano, São Paulo, $3^{a}$ edição revista, ampliada e atualizada, ed. Saraiva, 2012.

PIOVESAN, Flavia. ANTONIAZZI, Mariela Morales (coord.), Estudos Avançados de Direitos Humanos -- democracia e integração jurídica: emergência de um novo Direito Público, São Paulo, Campus Elsevier, 2013.

PIOVESAN, Flávia. Direitos Humanos e o Direito Constitucional Internacional, $14^{\mathrm{a}}$ ed. revista e atualizada, ed. Saraiva, São Paulo, 2013.

TRINDADE, ANTÔNIO AUGUSTO CANÇADO. ROBLES, MANUEL E. VENTURA. El Futuro de la Corte Interamericana de Derechos humanos. $2^{\mathrm{a}}$ ed. atualizada e ampliada, San José/Costa Rica, Corte Interamericana de Direitos Humanos e ACNUR, 2004.

VENTURA, Deisy. PIOVESAN, Flávia. KWEITEL, Juana. Sistema Interamericano sob Forte Ataque, Folha de São Paulo, p. A3, 07 de agosto de 2012. 